\title{
BMP signalling facilitates transit amplification in the developing cerebellum
}

Rook $\mathrm{V}^{1,2,3}$, Haldipur $\mathrm{P}^{4,5}$, Millen $\mathrm{K}^{4}$, Wingate $\mathrm{RJ}^{2}$, Butts $\mathrm{T}^{6}$.

${ }^{1}$ School of Biological and Chemical Sciences, Queen Mary University of London.

${ }^{2}$ Department of Developmental Neurobiology, King's College London.

${ }^{3}$ Department of Cell and Developmental Biology, University College London.

${ }^{4}$ Centre for Integrative Brain Research, Seattle Children's Research Institute, University of Washington.

${ }^{5}$ Great Ormond Street Institute of Child Health, University College London.

${ }^{6}$ Department of Molecular Physiology and Cell Signalling and School of Life Sciences, University of Liverpool.

\section{ABSTRACT}

The external granule layer (EGL) is a transient proliferative layer that gives rise to cerebellar granule neurons and drives the foliation of amniote cerebella. The formation of and differentiation from the EGL is incompletely understood, though BMP signalling has been implicated. Here, we characterise active BMP signalling during cerebellar development in chick and human and show that while in chick BMP signalling correlates with EGL formation, humans maintain BMP signalling throughout the EGL after the onset of foliation. Using in ovo electroporation in chick, we show that BMP signalling is necessary for EGL formation, but not for granule neuron fate. Our data are also consistent with a second role for BMP signalling in driving differentiation of granule progenitors in the EGL. These results elucidate two key, temporally distinct roles for BMP signalling in organising first the assembly of the EGL and then the tempo of granule neuron production within it.

\section{INTRODUCTION}

Transit amplification is a significant substrate for adaptation in the development of complex neural circuitry. In both the neocortex and cerebellum, the elaboration of specialised laminae 
supporting secondary proliferation is associated with increased foliation and complexity. Specialised sub-ventricular cell types which are either diminished or absent in mice, are expanded in the human cortex (Hansen et al., 2010; Heide et al., 2020) and, as recently shown (Haldipur et al., 2019), uniquely characterise the human cerebellar rhombic lip. In the cerebellum, tetrapods display a transient, superficial layer of neural precursors, the external granule layer (EGL) (Iulianella et al., 2019), which like the cortical subventricular zone is the site of transit amplification, but in this case only of a single cell type: the cerebellar granule neuron. Across different species, the degree of proliferation corresponds to the subsequent degree of elaboration of cerebellum morphology into folia. In the small, unfoliated amphibian cerebellum, the EGL is non-proliferative (Gona, 1976; Butts et al., 2014b). By contrast, in the foliated cerebellum of mammals and birds, the EGL is packed full of transit amplifying granule cell precursors.

The EGL provides a superb model for understanding how transit amplification is regulated and is also clinically significant as the site of unregulated proliferation that gives rise to medulloblastoma, a devastating childhood brain tumour. The implication of Sonic Hedgehog (Shh) signalling in a large minority of medullblastoma (Pietsch et al., 1997; Raffel et al., 1997; Vorechovsky et al., 1997) led to an examination of the role of Purkinje cell derived Shh signals in regulating EGL proliferation (Dahmane and Ruiz I Altaba, 1999; Wallace, 1999; Wechsler-Reya and Scott, 1999). Granule cell neurons that migrate through the Purkinje cell layer into the internal granule cell layer are the product of multiple rounds of symmetric division in the overlying EGL (Espinosa and Luo, 2008; Nakashima et al., 2015; Yang et al., 2015). Purkinje cellderived Shh boosts granule cell precursor proliferation in the EGL and when Shh signalling is reduced or increased, the cerebellum is smaller or larger, respectively (Corrales et al., 2004; Corrales et al., 2006).

Proliferative behaviour in the EGL is intimately linked to a transition in migratory behaviour from tangential to radial (Singh and Solecki, 2015), a process driven by complex cytoskeletal rearrangements (Trivedi et al. 2017). This transition has recently been shown to be influenced by the level of vascularisation of the EGL and the associated oxygen tension during postnatal development (Kullmann et al. 2020). However, the signalling factors that modulate and terminate transit amplification and their underlying mechanisms of action are poorly understood. Recent evidence has suggested that signalling through the p75 neurotrophin receptor and Bone Morphogenetic Protein (BMP) pathways regulate cell cycle exit of granule progenitors. While removal of the $\mathrm{p} 75$ receptor elicits corresponding phenotypes of delayed cell cycle exit and larger 
cerebella (Zanin et al., 2016, 2019), the functions of the BMP pathway in cerebellar development have proved complex.

BMP signalling has a well-established function in promoting dorsal fate specification in the central nervous system (Hegarty et al., 2013; Bier and De Robertis, 2015), and the EGL is derived from the most dorsal aspect of the cerebellar neuroepithelium, the rhombic lip (Alder et al., 1996; Machold and Fishell, 2005; Wang et al., 2005). During early development, rhombic lip specification is dependent upon BMP signalling (Chizhikov et al., 2006; Machold et al., 2007). However, EGL progenitors are specified following conditional deletion of BMP receptors 1a and 1b (Qin et al., 2006), intracellular Smad transducers of BMP signalling (Fernandes et al., 2012; Tong and Kwan, 2013), and an upstream regulator, Meis1 (Owa et al., 2018). Nevertheless, these conditional alleles all result in cerebella that are smaller and have reduced foliation, suggesting that BMP signalling is required for normal cerebellum expansion. In contrast, in vitro, BMP signalling antagonises Shh responses in granule cells (Rios et al., 2004) and promotes differentiation (Zhao et al., 2008; Ayrault et al., 2010), suggesting that its role is to supress proliferation. In both cases, the significance of BMP signalling for granule precursor behaviour is unclear given evidence of relatively low levels of BMP signalling in the EGL within the mouse cerebellum at P0 (Qin et al., 2006) and P4 (Rios et al., 2004), around the time that folia are beginning to grow (Sudarov and Joyner, 2007).

To directly address the question of whether and how BMP signalling affects cells within the EGL we assessed BMP signalling during EGL formation and subsequent foliation in human and chick, and took advantage of the ability to experimentally manipulate BMP signalling in a targeted manner in the developing avian cerebellum. We show that granule cell precursors transduce BMP signals as the EGL forms. As the avian but not the human cerebellum form folia, responses become confined to differentiating cells. Correspondingly, blocking BMP responses in a cell autonomous fashion in chick prevents EGL formation, while upregulating a constitutively active BMP receptor drives granule cells towards precocious differentiation. Our observations suggest that BMP signalling has two distinct phases during EGL development: as well as being responsible for terminal granule differentiation, BMP signalling drives tangential migration and EGL formation, and thereby facilitates the transit amplification that characterises the amniote cerebellum. 


\section{RESULTS}

\section{Granule cells transduce BMP signals differentially across development and species}

We used an antibody against phospho(p)Smad to log BMP signalling throughout cerebellar development (Figure 1a). At E5 (Figure 1b), pSmad expression is limited to cells proximal to the interface between the neurogenic neuroepithelium and the non-neurogenic roof plate, the rhombic lip. As the EGL is assembled at the pial surface up to E8 (Figure 1c), pSmad expression is uniform throughout the subpial layer. The expression of pSmad decreases in the EGL and becomes discontinuous in the granule lineage as the cerebellum begins to form folia from E10 (Figure 1d), with strong expression in the inner granule layer (IGL). By E14, expression of pSmad is seen in only a small number of EGL granule cell precursors at the crests of folia (Figure 1e, h) and is entirely absent from the EGL in the fissures (Figure 1f, h). This correlates with differences in the Purkinje cell layer, which is disorganised at the crests (Figure 1e) but in fissures comprises a uniform monolayer comparable to its mature organisation (Figure 1f). At this stage, pSmad is strongly expressed throughout the Purkinje cell and internal granule cell layer (Figure 1e, f, h). Correspondingly, in situ hybridisation for BMP ligands BMP2 and 4 and receptors BmpR1a and BmpR1b reveals strong expression in the EGL at E10 but preferential expression in folia crests by E14 (Figure 1g). Likewise, BMP receptors BmpRIa and BmpR1b also show consistent expression throughout the EGL at E10 but an upregulation within the folia crests at E14. 
bioRxiv preprint doi: https://doi.org/10.1101/2020.10.12.335612; this version posted October 12, 2020. The copyright holder for this preprint (which was not certified by peer review) is the author/funder. All rights reserved. No reuse allowed without permission.
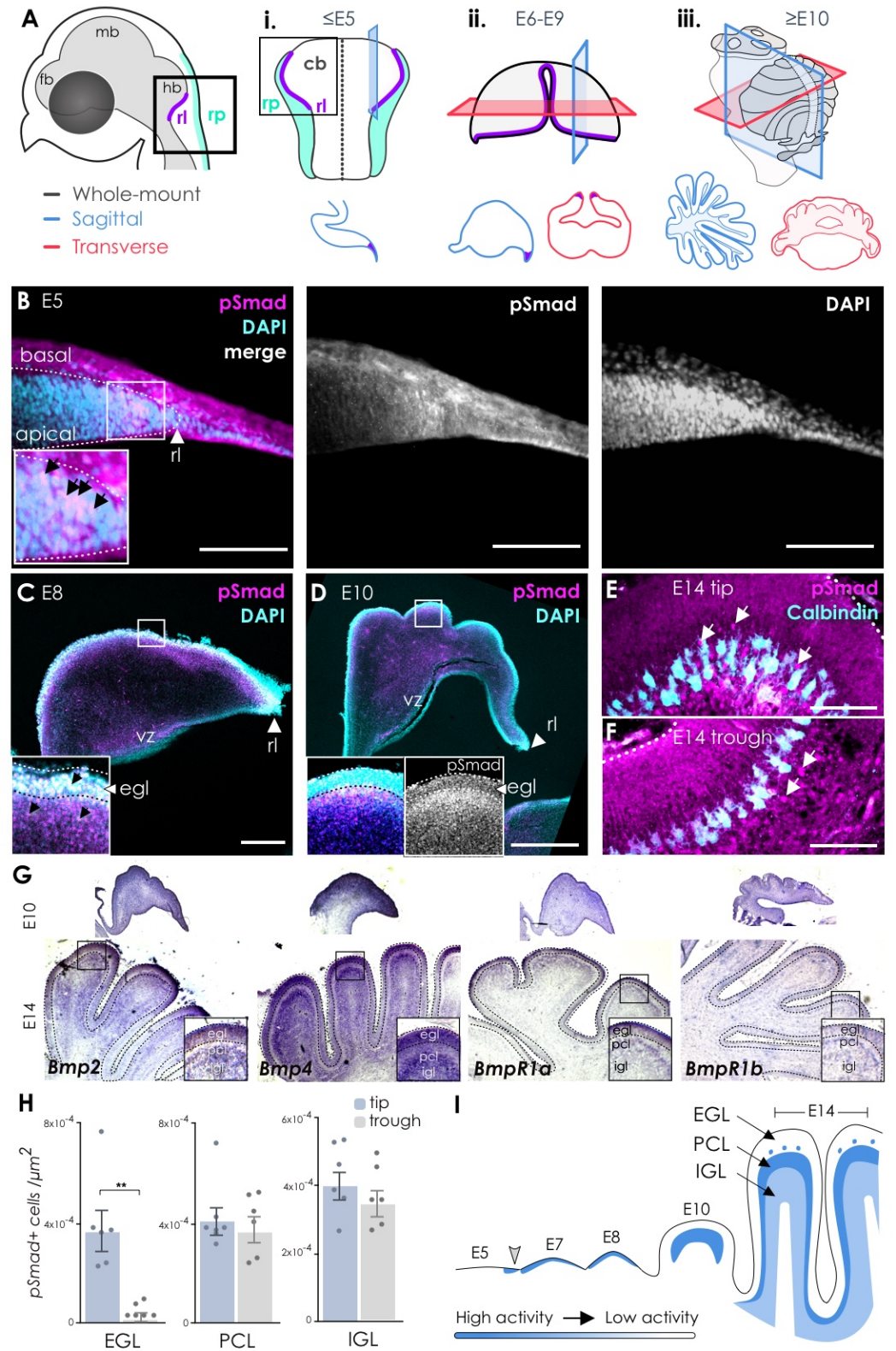

Figure 1:

\section{Characterisation of \\ BMP activity}

\section{throughout cerebellar development.}

(A) A schematic showing the anatomical location of the forebrain $(\mathrm{fb})$, midbrain (mb), hindbrain (hb), rhombic lip (rl) and roof plate (rp) in the chick embryo. Planes of section used throughout this study were; wholemounted, flattened hindbrains (Ai), sagittal (blue outline) and transverse (red outline; Ai, ii) sections. An antibody against the phosphorylated 3' serine residues of Smad1/5/9 (pSmad) shows the spatial requirements of BMP activity at the $\mathrm{E} 5$ rhombic $\operatorname{lip}(\mathrm{B}, \mathrm{n}=3)$, during $\mathrm{EGL}$

establishment at E8 (C, n=3), at the onset of proliferation in the E10 EGL as folia develop $(C, n=2)$ and at highly proliferative and foliated stages of cerebellum development (E, F; E14, n=6). (G) mRNA 
expression of BMP ligands $(B m p 2,4)$ and receptors $(B m p R 1 a, b)$ at E10 (n=3) and E14 (n=4). (H) Spatial distribution of pSmad expression in the lamina layers (EGL; external granule layer, PCL; Purkinje cell layer and IGL; inner granule layer) of the crests (blue bars, E) and fissures (grey bars, F) of sagittally sectioned E14 cerebellum ( $n=6$ sections from 4 cerebella). Quantification of pSmad expression shows that BMP activity is significantly higher in the EGL of the folia crests compared to the fissures $(\mathrm{G} ; \mathrm{p}=$ 0.0015; mean $\pm \mathrm{SEM}=3.521 \mathrm{e}-005 \pm 8.116 \mathrm{e}-006)$, however no significant differences in activity were observed between the PCL and IGL.(I) A summary of BMP activity during EGL formation and folia development in the chick (E5-E14). Scale bars B, E; $25 \mu \mathrm{m}, \mathrm{C}-\mathrm{D} ; 50 \mu \mathrm{m}$.

Taken together, our data (Figure 1g) suggest differing patterns of BMP signalling before and after the initiation of foliation. To explore whether this is conserved in the much more foliated human cerebellum, we assessed pSmad expression during early initial stages of foliation (13pcw of human development, Figure 2a-f) and later stages (19pcw, Figure $2 \mathrm{~g}-\mathrm{l}$ ), when foliation is well underway. Formation of the human EGL is apparent by pcw10 (Figure 2a), and in common with mouse and chick, the initiation of foliation is coincident with the onset of Shh expression in developing Purkinje neurons, such that foliation and Shh expression are obvious by pcw12 (Figure 2b). As in chick, pSmad expression is present in the Purkinje cells and the internal granule layer, both at early (Figure 2c, d, e) and later foliation stages (Figure 2i, j, k). Again as in chick, at later foliation stages (pcw19) we observed a difference in the maturation of Purkinje neurons between folia crests and fissures, with a more mature monolayer being present in fissures. However, unlike the situation in chick, pSmad expression after the onset of foliation is observed in the EGL in both folia crests (Figure 2d, j) and fissures (Figure 2e, k) at both early (Figure 2c, d, e) and later (Figure 2i, j, k) stages of folia development. 

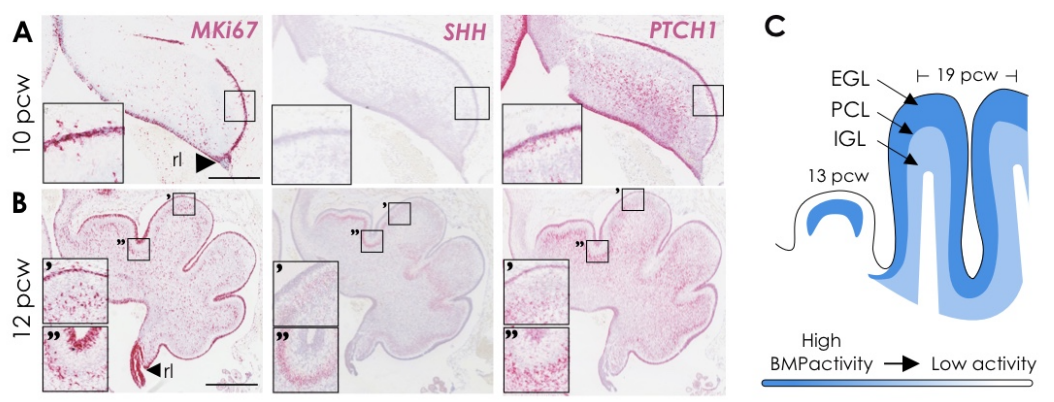

D

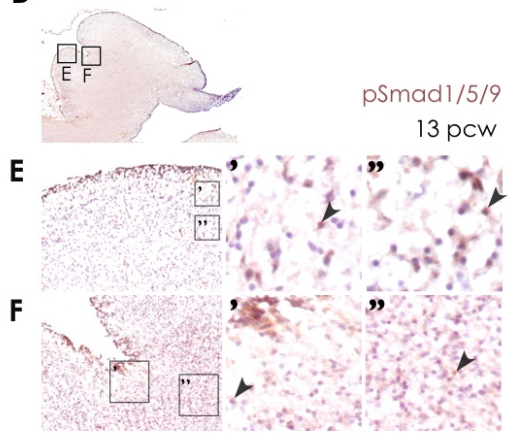

J

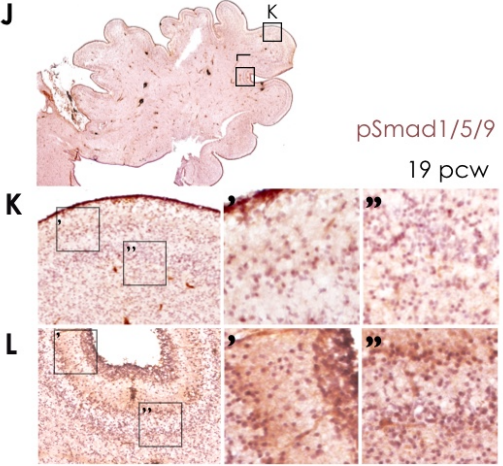

G

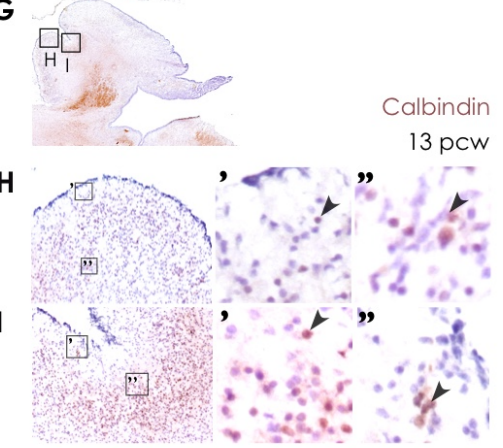

M

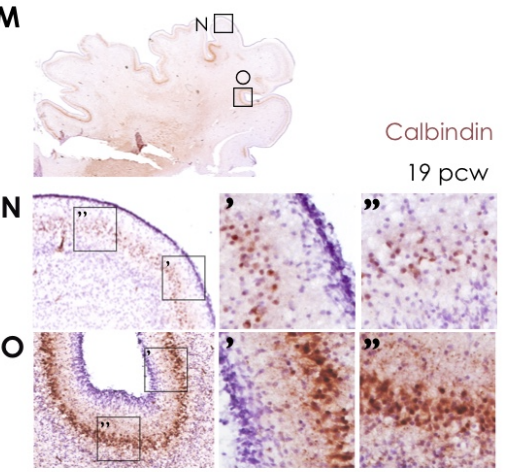

Figure 2: Shh

expression and BMP

activity in the

embryonic human

cerebellum.

Expression of the

proliferation marker

Ki67, SHH and Shh

receptor $P A T C H E D 1$

(PTCH1) during EGL

establishment in the

10pcw $(\mathrm{A} ; \mathrm{n}=2)$ and

during early foliation in

the $12 \mathrm{pcw}(\mathrm{B} ; \mathrm{n}=1)$

human cerebellum. BMP

activity, summarised in

(C), is observed

throughout the $13 \mathrm{pcw}$

human cerebellum (D,

$n=2)$ folia crests (E) and

fissures (F). Calbindin

expression in the $13 \mathrm{pcw}$

cerebellum $(\mathrm{G})$ folia crests $(\mathrm{H})$ and fissures $(\mathrm{I})$ shows the early migration of Purkinje cell precursors.

BMP activity in the $19 \mathrm{pcw}$ cerebellum $(\mathrm{J} ; \mathrm{n}=2)$ is observed in the EGL of the folia crests $(\mathrm{K})$ and to a lesser extent in the EGL of the fissures (L). Calbindin expression in the 19pcw cerebellum (M) shows a less organised Purkinje cell layer in the folia crests $(\mathrm{N})$ compared to the fissures $(\mathrm{O})$. Scale bar A; $500 \mu \mathrm{m}$.

BMP signalling is required for the assembly of the EGL 
To determine the role of BMP signalling during the early assembly of the EGL, we used a targeted electroporation in chick at the rhombic lip at E4 (to predominantly target granule cell precursors) of a negative intracellular BMP regulator Smad6 (Xie et al., 2011) or a constitutively active BMP regulator Smad1EVE, a variant of the transcription factor Smad1 in which the Nterminal SVS residue that is phosphorylated during activation is changed to EVE, (Fuentealba et al., 2007; Song et al., 2014).

We first confirmed that our constructs were able to affect BMP signal transduction in a predictable manner by characterising the expression of pSmad 2 days after overexpression of control, Smad1EVE, and Smad6 constructs at E3. As expected, pSmad expression was either unchanged, upregulated in a cell autonomous manner or abolished, respectively (Figure 3a).

Electroporation of a control tdTomato (tomato) construct into the cerebellar rhombic lip at E4 results in the labelling of the assembling EGL at E7 (Figure 3b). Upregulation of BMP signal transduction by overexpression of Smad1EVE at E4 resulted in tangential migration of EGL cells in a subpial pattern similar to that seen in control electroporations, albeit with a partial depletion of the EGL distal to the rhombic lip (Figure 3c). In contrast, inhibition of BMP signal transduction by overexpression of Smad6 resulted in a subpial cell-free layer in the position that a granule precursor-rich EGL would be expected to form. This cell free zone extended across the cerebellum from anterior to posterior and appears to contain axonal processes (Figure 3d). 
bioRxiv preprint doi: https://doi. org/10.1101/2020.10.12.335612; this version posted October 12, 2020. The copyright holder for this preprint (which was not certified by peer review) is the author/funder. All rights reserved. No reuse allowed without permission.
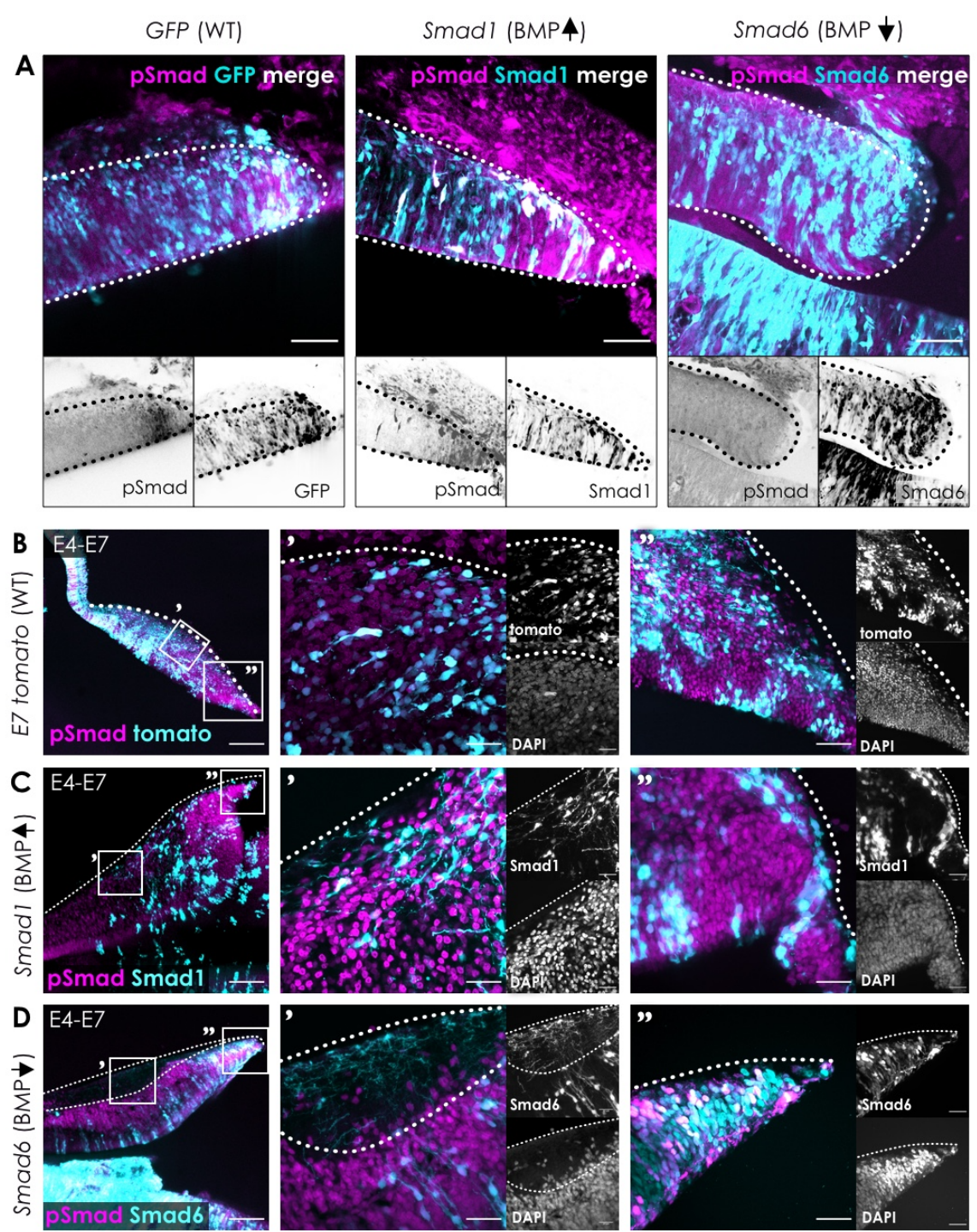
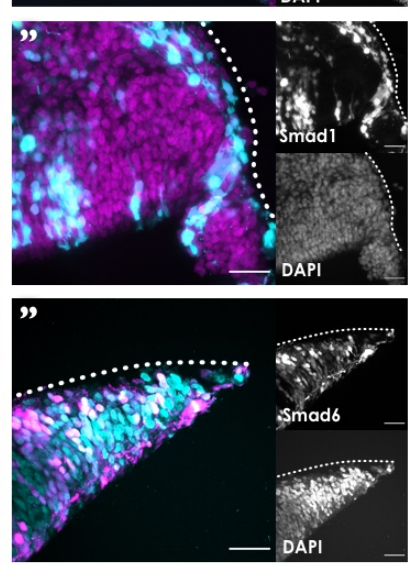

Figure 3: BMP

signalling is required

for establishing the

external granule layer.

(A) E3 hindbrains were

electroporated with

pCAß-GFP alone ( $n=3)$,

or in combination with

pCAß-Smad1EVE-IRES-

GFP (Smad1; BMP $\uparrow$;

$\mathrm{n}=3$ ) or pCAß-Smad6

(Smad6; BMP $\downarrow ; n=3$ ),

incubated to $\mathrm{E} 5$, then

embedded in gelatine and

sectioned sagittally at

$100 \mu \mathrm{m}$. Sections were

then immunolabelled

using an antibody against

phosphorylated

Smad1/5/9 (pSmad) to

confirm either no change

in BMP activity (WT), or

up- or down-regulation of

BMP signalling at the rhombic lip in Smad1::GFP and Smad6::GFP electroporated embryos, respectively.

E4 embryos were electroporated with pCAß-tdTomato alone $(B, n=3)$, or in combination with Smad1

(BMP $\uparrow ; C, n=7)$ or Smad6 (BMP $\downarrow ; D, n=7)$, further incubated to E7 and then sagittally sectioned.

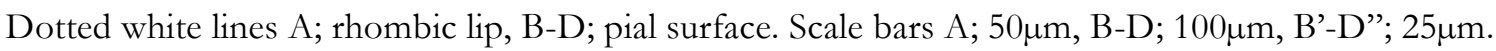




\section{BMP signalling affects tangential migration but not the specification of granule cells}

In order to explore the cell autonomous effects of our manipulations upon cellular migratory behaviour, we examined the morphology of cells migrating away from the rhombic lip. We first re-examined the normal time course of granule cell differentiation from our control embryos electroporated with tomato at E4 and harvested at E7. Granule cell precursors exhibit a variety of morphologies consistent with the reported steps of proliferation and early migration within the EGL (Hanzel et al., 2019), with migrating granule cell precursors being predominantly bipolar or unipolar (Figure 4a). However, no cells at this age had yet entered the internal granule cell layer and adopted the T-shape axonal morphology that characterises definitive granule cells after their exit of the EGL.

Because granule cell precursors undergo multiple rounds of division, electroporated constructs are rapidly diluted and no longer expressed in the EGL by E10. To log the acquisition of definitive morphologies by granule cells we therefore took advantage of the Tol 2 transposon system (Sato et al., 2007) to indelibly label granule cell progenitors and their progeny in a mosaic fashion at E2 and examined the cerebellum at E14, once granule differentiation is well under way (Figure 4b). At E14, the internal granule cell layer is occupied by granule cells with T-shaped axons.

When we experimentally manipulated BMP signalling, we first observed that following electroporation at E3, down-regulation of BMP signal transduction decreases migration away from the rhombic lip, whereas up-regulation promotes it (data not shown). When we examined the progeny at E7 of rhombic lip cells that had been electroporated with Smad6 at E4, we were surprised to find a preponderance of mature granule cell morphologies (Figure 4c). This suggests that not only are cells still produced at the rhombic lip but that these are able to develop precociously into definitive granule neurons despite the absence of a transit amplifying EGL (Figure 3d). These results indicate that BMP signalling is not required for cells to be generated at the rhombic lip and undergo differentiation into granule neurons. Rather, tangential migration leading to the formation of an EGL is inhibited when BMP signalling is perturbed.

When we examined cells expressing the constitutively active BMP receptor Smad1EVE, we were again surprised to find mature granule neuron morphologies amongst labelled cells deep to the EGL (Figure 4d). In contrast to downregulation of BMP signal transduction (Figure 4c), we also observed morphologies consistent with those of normal granule cell precursors of the EGL 
(Figure 4a). Cell autonomous upregulation of BMP signal transduction thus produces a complex result where some cells retain a progenitor identity while others differentiate prematurely into neurons with T-shaped axons.

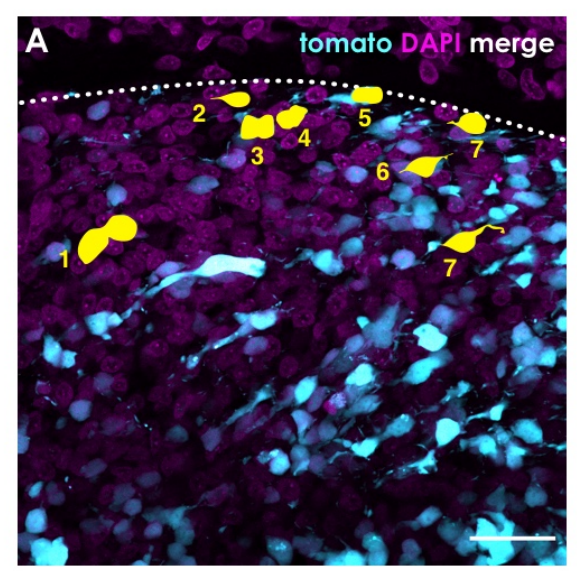

A' E4-E7 control (tomato)

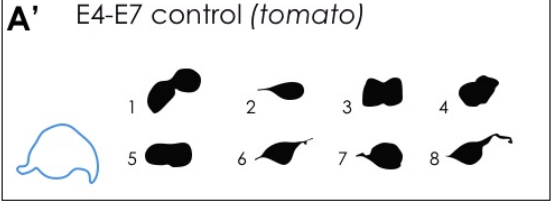

C E4-E7 Smad6 (BMP \)

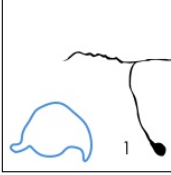

D E4-E7 Smadl (BMP $\mathbf{4})$

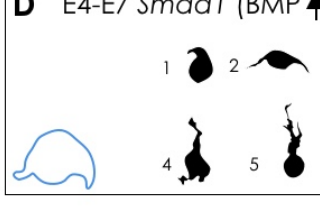

\section{.}

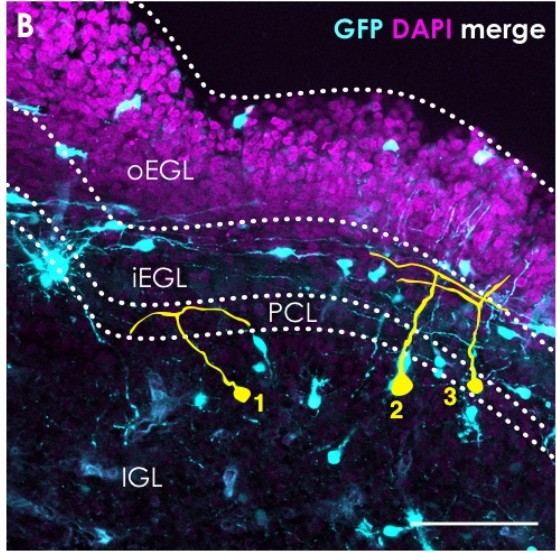

B' E2-E14 control (tol2::gfp)

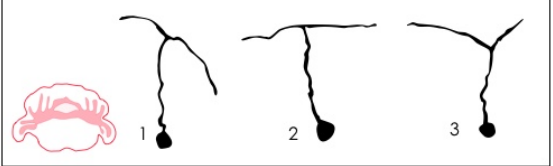

-
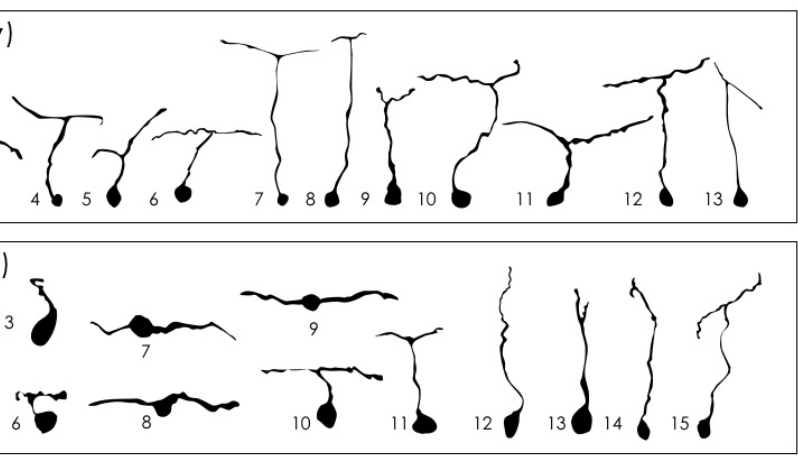

Figure 4: BMP

signalling is required

for the initial tangential

migration of rhombic

lip derivatives.

(A) Sagittal sections from

E7 embryos

electroporated at E4 with tomato control DNA

show migrating or

proliferative granule

precursor cells (cell traces

A, A') towards the pial

surface (dotted white

line). (B) To visualise

granule cell morphologies

at a foliated stage of

development, embryos

were electroporated at

E2 with tol2::GFP and

tol2-transposase and sectioned transversely at E14 (cell traces; B'). Cell traces from the E14 cerebellum show classic T-shaped axon and parallel fibre morphologies (B'), which are also observed following knock-down of BMP signalling at E7 (C). Following upregulation of BMP signalling at E7, granule cell morphologies are varied, showing various stages of granule cell maturation (D). Scale bars A; 200 $\mu \mathrm{m}, \mathrm{C}$, D; $25 \mu \mathrm{m}$. C'-F cell traces not to scale.

Upregulation of BMP signalling reveals a temporal switch in GCP responsiveness at E8, coinciding with an increase of $\mathrm{SHH}$-induced proliferation

Our results at E7 led us to look closely at events in the EGL between E7 and E8, which is a critical developmental step in the development of the cerebellum. By E8, proliferation has significantly increased within the EGL (Figure 5a,d) and this correlates with a sharp increase in 
Ptch1 expression (a readout of Shh signalling) within the EGL (Figure 5b). EGL thickness also increases 4-fold between E7 and E8 (Figure 5c). Correspondingly, labelling of the rhombic lip by electroporation at $\mathrm{E} 4$ yields cellular morphologies indicative of proliferative divisions in the outer EGL (Figure 5e, f).

Upregulation of BMP signal transduction at E4 results in accelerated granule cell development and a partial loss of EGL at E7 (Figure 3c). Examining the results of the same manipulation a day later at E8, we find that the EGL is completely depleted of cells (Figure 5g). Cell tracing reveals that the majority of labelled cells bear the hallmarks of mature granule cell morphology: a cell body within the inner granule layer and a T-shaped axon (Figure 5h). The cell-free EGL can be seen to be filled with parallel fibres, reminiscent of an early-forming molecular layer (Figure 5g). Quantification of EGL cell density at E7 and E8 following electroporation shows that both upregulation and downregulation of cell autonomous BMP signal transduction results in a similar loss of EGL by E8 (Figure 5i) and premature granule cell differentiation. However, our examination of the differing patterns of cellular behaviour suggest that this reflects different developmental processes, with the EGL never forming when BMP signalling is inhibited but being prematurely depleted when BMP signalling is upregulated. 
bioRxiv preprint doi: https://doi.org/10.1101/2020.10.12.335612; this version posted October 12, 2020. The copyright holder for this preprint (which was not certified by peer review) is the author/funder. All rights reserved. No reuse allowed without permission.
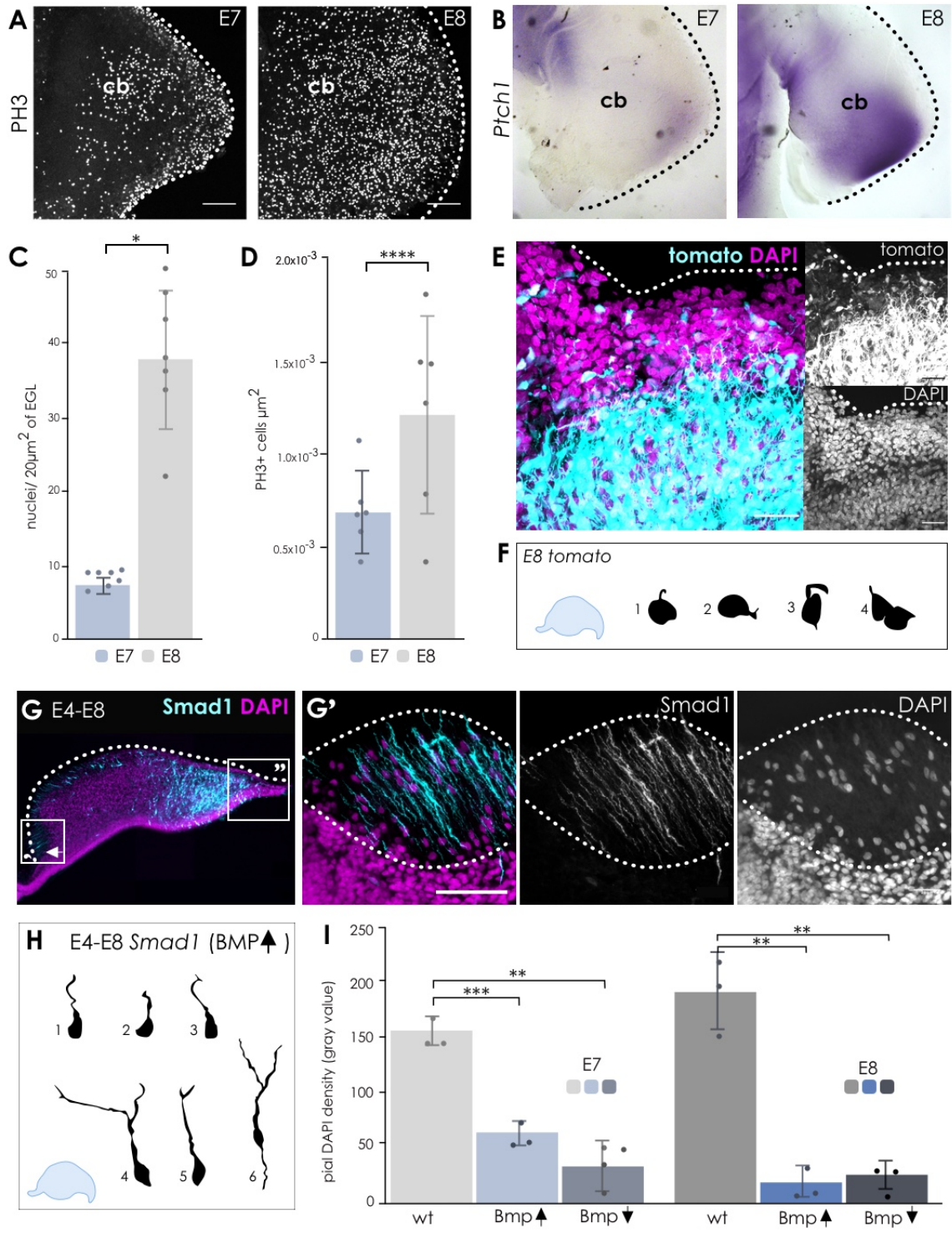

Figure 5: Upregulation of BMP signalling

reveals a temporal switch in GCP

responsiveness at E8, coinciding with the onset of SHH-induced proliferation. (A)

Proliferation at the pial surface significantly increases between E7 and E8 ( $\mathrm{p}=0.0465$, mean \pm $\mathrm{SEM}=0.0005322 \pm$ $0.0002344 ; n=6$ for both E7 and E8), which coincides with the onset of Shh signalling at E8, as determined by expression of Ptch1 mRNA (B). The nuclei density within the EGL (C) significantly increases between E7 and $\mathrm{E} 8$, as determined by the number of DAPI-

positive nuclei per $20 \mu \mathrm{m}^{2}$ bin of the EGL ( $\mathrm{n}=6$ bins per sample from $\mathrm{n}=7$ for $\mathrm{E} 7$ and $\mathrm{n}=7$ for $\mathrm{E} 8$; $\mathrm{p}<0.0001$, mean $\pm \mathrm{SEM}=30.37 \pm 3.556)$. Quantification of PH3 immunolabelling (D) of the wholemounted cerebella (A) shows that there is a significant increase in proliferative activity between E7 and $\mathrm{E} 8(\mathrm{p}=0.0465$, mean $\pm \mathrm{SEM}=0.0005322 \pm 0.0002344 ; \mathrm{n}=6$ for both $\mathrm{E} 7$ and $\mathrm{E} 8)$. In a control cerebellum electroporated with tdTomato at E4 and sagittally sectioned at E8 (E; $n=3)$, granule cell precursors still exhibit migrating or proliferative morphologies (F). In embryos electroporated at E4 with Smad1 and sectioned sagittally at E8 (G; $n=4)$, an anterior-posterior gradient of EGL loss is observed, with a molecular layer forming in place of the EGL $\left(G^{\prime}\right)$, within which fibres can be seen extending (Smad1, cyan) and sparse DAPI labelling. (H) Granule cells in the Smad1-electroporated E8 cerebellum 
exhibit more mature granule cell morphologies. (I) To show the extent of the depletion of the EGL in control (wt), Smad1 (Bmp $\uparrow)$ and Smad6 (Bmp $\downarrow)$ electroporated cerebella, the fluorescent intensity of DAPI labelling at the pial surface was quantified ( $n=3$ samples quantified for each condition at each developmental stage). Significant losses of DAPI density was observed at both E7 and E8 for Smad1 (E7; $\mathrm{p}=0.0176$, mean $\pm \mathrm{SEM}=92.33 \pm 12.41, \mathrm{E} 8 ; \mathrm{p}=0.0073 ;$ mean $\pm \mathrm{SEM}=173.7 \pm 14.97, \mathrm{n}=3$ per condition $)$ and Smad6 $(E 7 ; p=0.0046$, mean \pm SEM $=-124.4 \pm 8.446, E 8 ; p=0.0248 ;$ mean \pm SEM $=165.8 \pm 26.58, \mathrm{n}=3$ per condition). Scale bars A; $200 \mu \mathrm{m}, \mathrm{E}, \mathrm{G} ; 25 \mu \mathrm{m}$. Cell traces in $\mathrm{F}$ and $\mathrm{H}$ not to scale.

\section{DISCUSSION}

In this study we have shown that BMP signalling is active in complex and spatiotemporally dynamic patterns across cerebellar development in both chick and human. In chick, the BMP signalling components are prominently expressed in the early phases of EGL formation becoming increasingly restricted to the crests of folia as development proceeds. This corresponds to the distribution of pSmad, which disappears from the EGL as folia are generated. In contrast, in humans BMP signalling throughout the EGL is maintained into foliation stages. Manipulation of this signalling in chick has revealed that BMP signalling is not directly linked to granule neuron fate, but to tangential migration and recruitment to the EGL. Phosphorylated Smad1/5/9 (pSmad) expression and experimental up- and downregulation suggest a transition in BMP signalling function to promotion of granule differentiation once the EGL has formed.

\section{Granule cell differentiation is independent of EGL formation}

Our observations add to a growing body of evidence that the intricate choreography of developmental stages of granule cell differentiation during inward migration via the EGL first described by Cajal (Cajal, 1894) is not required to produce T-shaped granule cell axons known as parallel fibres. In Cajal's scheme, after terminal migration cells exit the EGL, migrating inwards with a leading dendritic process, leaving their T-shape axons behind to extend through the molecular layer. While this sequence of events may be less stereotyped than Cajal presumed (Hanzel et al., 2019), development of granule cells takes place in the absence of these steps in ray- 
finned fish which do not exhibit a transient transit amplifying layer within the cerebellum (Kaslin et al., 2009; Chaplin et al., 2010; Butts et al., 2014c).

\section{Granule cell specification is independent of BMP signalling}

Our results challenge the expectation that granule cell production would explicitly depend on a cascade of induction that initiates with BMP signalling at the rhombic lip. Classical experiments showed that BMP can induce granule cells in culture (Alder et al., 1999). Correspondingly, specialised BMP-expressing cells sit adjacent to rhombic lip precursors at the rhombic lip (Chizhikov et al., 2006; Campo-Paysaa et al., 2019). Expression of BMP/Gdf in these cells is dependent on notch activation by adjacent neural cells (Broom et al., 2012). However, conditional mouse mutants that interrupt the BMP pathway give rise to early rhombic lip phenotypes (Qin et al., 2006; Fernandes et al., 2012; Tong and Kwan, 2013), and a dependence of EGL cell production on BMP signalling has never been shown in vivo.

Our results show that manipulating BMP signalling does not result in the loss of granule progenitors but rather an alteration of either the trajectory (downregulation) or tempo (upregulation) of their development. Our observations suggest that BMP signalling is required only for the maintenance of a subpial localisation of migrating granule cell precursors adjacent to, and possibly in intimate contact with (Hausmann and Sievers, 1985), the basal lamina. Correspondingly, gain of BMP signal transduction leads to cells directly joining a subpial migration pathway but still undergoing their normal differentiation (Figure 6). 
Development

\section{Control}

Smad1 (BMP4)

Smad6 (BMP $\downarrow)$

External granule layer
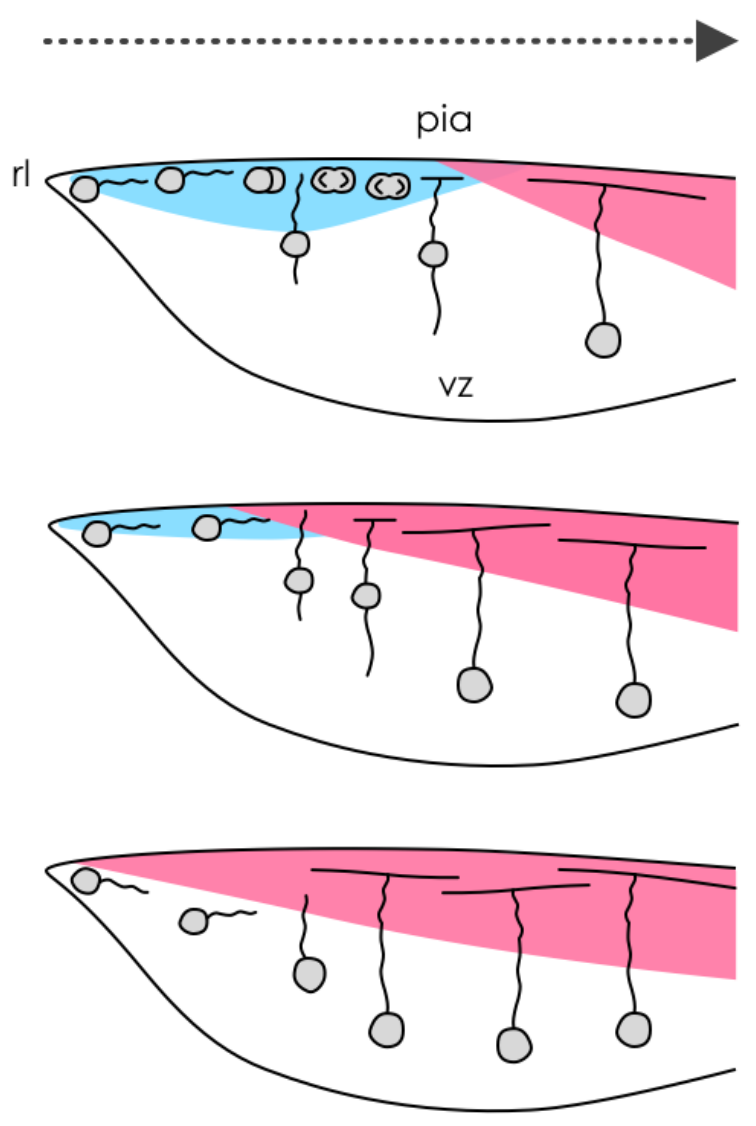

Molecular

layer
Figure 6: Tightly

regulated

spatiotemporal activity of the BMP signalling pathway is required for proper development of the external granule

layer. In control

cerebella, granule cell precursors (grey circles) migrate tangentially from the rhombic lip (rl) across the pial surface to form the external granule layer (blue), where they undergo massive transit amplification before they exit the cell cycle, differentiate and migrate radially towards the inner granule layer, eventually leaving behind a

molecular layer (pink) in which their parallel fibres extend. In cerebella with increased levels of BMP signalling (Smad1, BMP $\uparrow$ ), granule cells are initially recruited to the pial surface, however coinciding with the onset of Shh at E8 (in chick), the excess of BMP signalling forces granule cells to exit the cell cycle prematurely and migrate, leaving behind a molecular layer and a depleted cerebellum. Following inhibition of BMP signalling at the rhombic lip (Smad6, BMP $\downarrow$ ) cells fail to be recruited to the pial surface, and instead immediately migrate ventrally and radially, before extending parallel fibres in a disorganised arrangement into the molecular layer that forms at the pial surface. 
The conclusion of this line of evidence is that BMP signal transduction is at least permissive, if not instructive, for EGL formation. In its absence, cells fail to cling to the basal membrane as they migrate and fail to form a transit-amplifying layer. Similar results are found when NeuroD1, which marks the differentiation of granule cells, is overexpressed at the rhombic lip (Butts et al., 2014b; Hanzel et al., 2019) suggesting that the ability of granule cell precursors to suspend differentiation is intimately linked to the subpial location of granule cell precursors within the EGL. This germinal niche facilitates the mesenchymal-like cell behaviour that is seen in transit amplifying progenitors, including an absence of polarisation (Singh \& Solecki, 2015) that is regulated by both transcriptional (Singh et al. 2016) and post-transcriptional (Famulski et al. 2010; Trivedi et al. 2017; Kullman et al. 2020) mechanisms.

When BMP signal transduction is constitutively upregulated granule cells undergo normal tangential migration and form an EGL, but their passage through this transient layer seems to be abbreviated. Under these experimental conditions, by E8 the EGL rapidly depletes. One attractive explanation is that high levels of BMP signal transduction favour terminal division of granule cell precursors as opposed to symmetrical transit amplifying divisions that produce two precursors (Nakashima et al., 2015; Yang et al., 2015). The balance of transit amplifying versus terminal divisions is the key regulator of EGL expansion (Espinosa and Luo, 2008). When proliferation rates are upregulated by Shh in a background of constitutively raised BMP signal transduction, granule cell precursors undergo only terminal divisions, as has been observed in vitro (Rios et al., 2004; Zhao et al., 2008). Consequently, the EGL is rapidly cleared out to make a molecular layer.

This function of BMP in driving terminal differentiation within the EGL has significant parallels with the recently described role for BMP signalling in driving terminal differentiation and radial migration of upper layer cortical progenitors (Saxena et al., 2018): cortical glutamatergic neurons are derived from transit amplifying progenitors in the SVZ (Noctor et al., 2004) that in mouse models proliferate in response to experimentally induced Shh signalling, mimicking the endogenous condition in humans (Wang et al., 2016). Thus, BMP antagonism of Shh-driven proliferation may be a general mechanism for regulating terminal differentiation in large neuronal populations in the amniote brain. 


\section{BMP signalling in the EGL persists during initial foliation in human}

Given the function of BMP signalling in driving granule differentiation, the presence of $\mathrm{pSmad}$ staining throughout the early human EGL (upto pcw 19) after the onset of foliation (which occurs before pcw 12) is intriguing and is consistent with the idea that the human EGL has undergone a heterochronic shift in signalling to facilitate precocious granule neuron differentiation during the early weeks of foliation. Whether this signalling persists into later embryonic and post-embryonic development is an important remaining question. In mouse, phosphoSmad expression has been detected at the rhombic lip around the time of the initiation of production of granule neurons (Qin et al., 2006; Fernandes et al., 2012; Ma et al., 2020). Data relating to the granule lineage later in development, as with our results in chick, has exhibited variation across developmental time. While some reports have suggested that pSmad signalling is present in isolated inner EGL cells and throughout the inner granule layer (IGL) around postnatal day (P)0 (Qin et al., 2006) or P4 (Rios et al., 2004), more recent studies have suggested variation across the anterior-posterior extent of the EGL earlier in development at E14.5 (Ma et al., 2020) and E16.5 (Fernandes et al., 2012), and ubiquitous expression in both the EGL and IGL at P10 (Owa et al., 2018). Thus, BMP signalling appears to exhibit considerable modulation across developmental time in mouse, as we have observed in chick.

This correlates with the behaviour of granule cells. Shh signal transduction in the EGL begins around E16.5 in mouse (Lewis et al., 2004) and differentiation of granule neurons begins approximately a day later at E17.5 (Sudarov and Joyner, 2007), equating broadly with the onset of foliation. Thereafter, extensive transit amplification in the EGL and granule differentiation with radial migration happens throughout the first postnatal week. Data from clonal labelling (Espinosa and Luo, 2008; Legué et al., 2015) and genetically-inducible fate mapping (Legué et al., 2016) suggests that this process is largely complete by P10, at which point pSmad labelling is seen throughout the EGL and IGL (Owa et al., 2018), presumably driving terminal granule differentiation of remaining progenitors.

In human, maintenance of pSmad expression throughout the EGL suggests that signalling is being transduced comparatively earlier in the life history of granule cells than in mouse and chick during foliation. This shift is reminiscent of the late postnatal mouse EGL (Owa et al., 2018) and we suggest that it could represent an adaptation to enable increased production of granule neurons. The rhombic lip in humans has recently been shown to persist later in development 
than is the case in mouse, and to possess a subventricular zone that presumably facilitates the huge cell production that characterises the human cerebellum, particularly the posterior lobule (Haldipur et al., 2019). Our data are consistent with a model where, at least at early stages, there has also been an increase in the proliferative dynamics of the human EGL, and where the BMP signalling that we have observed drives the precocious differentiation of granule neurons beginning shortly after the initiation of foliation. Together with the persistence of the rhombic lip, BMP signalling alterations may thus contribute to the enormous numbers of granule neurons found in human (Azevado et al., 2009).

\section{BMP signalling as a regulator of the lifespan of the transient EGL}

While the central importance of Shh signalling in regulating the scale of transit amplification and growth of the cerebellum is clear from a wealth of studies (Butts et al., 2014a; Hibi et al., 2017), our data supports a key role for BMP signalling in managing the overall programme of transit amplification. In particular, we suggest that our experiments reconcile data that BMP both inhibits Shh responsiveness (Rios et al., 2004; Zhao et al., 2008; Ayrault et al., 2010) but is also required for a large cerebellum (Qin et al., 2006; Fernandes et al., 2012; Tong and Kwan, 2013). By facilitating EGL formation and then influencing the timing of differentiation, BMP signals are ideally placed to regulate the tempo of production of cells that populate the IGL. These observations are echoed by recent experiments showing that the temporal patterning of GABAergic cell production in the cerebellum is also regulated by BMP signalling (Ma et al., 2020). Thus the BMP pathway has multiple roles during cerebellar development in amniotes, amongst which are two distinct roles unrelated to fate within the granule lineage: driving EGL formation initially and then promoting differentiation following the onset of foliation.

\section{MATERIALS AND METHODS}

\section{In ovo electroporation}

Fertilised hen's eggs (Henry Stewart) were incubated at $38^{\circ} \mathrm{C}$ at $70 \%$ humidity. Electroporations were performed between stages HH10-25 (Hamburger and Hamilton, 1993), or between embryonic day 2 (E2) to E4. Eggs were windowed using sharp surgical scissors and the vitelline membrane covering the head removed. DNA was injected into the fourth ventricle at a final 
concentration of $1-3 \mu \mathrm{g} / \mu \mathrm{l}$ in addition to trace amounts of fast-green dye (Sigma). Three $50 \mathrm{~ms}$ square waveform electrical pulses at $5 \mathrm{~V}(\mathrm{E} 2)$ or $10 \mathrm{~V}(\geq \mathrm{E} 3)$ were passed between electrodes that were placed on either side of the hindbrain Figure 3a). Five drops of Tyrode's solution containing penicillin and streptomycin (Sigma) was administered on top of the yolk before being resealed and further incubated for the designated number of days. Embryos were fixed in $4 \%$ PFA in PBS for 1 hour at room temperature or overnight at $4{ }^{\circ} \mathrm{C}$ and then processed for histology. Table 1 summarises the DNA plasmid constructs used throughout this study.

Table 1: DNA plasmids

\begin{tabular}{lll}
\hline Plasmid & Details & Source/ reference(s) \\
\hline$p C A G G S-S m a d 6$ & BMP inhibitor & Andrea Streit, KCL (Xie et al., 2011) \\
\hline$p C A G G S-S m a d 1 E V E-I R E S-G F P$ & Constitutively activated Smad1 & $\begin{array}{l}\text { Andrea Münsterberg, UEA } \\
\text { (Fuentealba } \text { et al., 2007; Song et al., } \\
2014)\end{array}$ \\
\hline$p C A G G S$-GFP & GFP reporter & Richard Wingate, KCL \\
\hline$p C A G G S-t d$ Tomato & Tomato reporter & Nico Daudet, UCL (Sato et al., 2007; \\
\hline$p$ Tol2-GFP & Tol2 integrated GFP reporter & Freeman et al., 2012) \\
\hline$p$ Tol2-Transposase & Tol2 transposase enzyme & \\
\hline
\end{tabular}

\section{Human foetal tissue procurement}

Histological analysis of the human cerebellum: Human cerebellar samples used in this study were collected in strict accordance with legal ethical guidelines and approved institutional review board protocols at Seattle Children's Research Institute, University College London and Newcastle University. Samples were collected at by the Human Developmental Biology Resource (HDBR), United Kingdom, with previous patient consent. Samples were staged using foot length with the age listed as post-conception weeks ( $\mathrm{pcw}$ ), which starts from the point at which fertilization occurred.

Samples were fixed in 4\% PFA and then processed through alcohol gradients and xylene.

Processed tissue was then embedded in paraffin wax prior to sectioning. Samples sectioned using the cryostat were treated with $30 \%$ sucrose following fixation. Paraffin and cryo-sections were collected at 4 and $12 \mathrm{~m}$ respectively. In situ hybridization assays were run using commercially available probes from Advanced Cell Diagnostics, Inc. Manufacturer recommended protocols were used without modification. The following probes were used in the study SHH (\#600951), MKI67 (\#591771) and PTCH1 (\#405781). Sections were counterstained with fast green. Images 
were captured at 20X magnification using a Nanozoomer Digital Pathology slide scanner (Hamamatsu; Bridgewater, New Jersey).

\section{Tissue processing, immunohistochemistry, in situ hybridisation and imaging}

Cerebella were dissected between E5-E14 and either whole-mounted in glycerol or embedded in $20 \%$ gelatine, $4 \%$ low-melting point (LMP) agarose or OCT and sectioned at 50 $\mu \mathrm{m}$ using a vibratome (Leica) or at $15 \mu \mathrm{m}$ using a cryostat (Microm). For immunolabelling, whole-mount and gelatine sections were washed with PxDA (1x PBS, 0.1\% Tween-20, 5\% DMSO, 0.02\% $\mathrm{NaN}_{3}$ ), then 3x 30 minutes, blocked (PxDA, 10\% goat serum) 2x 1 hour, and incubated in primary antibody (diluted in block) for 48 hours at $4^{\circ} \mathrm{C}$ on a rocker. Tissue was washed in block for 5 mins then 3x 1 hour. Secondary Alexaflour (Thermofisher) antibodies were diluted in block (1:500) and incubated overnight at $4^{\circ} \mathrm{C}$. Samples were washed $3 \mathrm{x} 1$ hour with block, $3 \mathrm{x} 3$ mins with PxDA and 1 hour in 4\% PFA. Sections were mounted using Fluoroshield containing DAPI (Abcam). Frozen sections were thawed at room temperature for 1 hour, washed in 1x TBS buffer ( $2 \% \mathrm{BSA}, 1 \mathrm{x}$ TBS, $\left.0.02 \% \mathrm{NaN}_{3}, \mathrm{pH} 7.6\right)$, blocked in 1x TBS buffer for 10 minutes, and incubated in primary (diluted in $1 \mathrm{x}$ TBS) overnight at room temperate in a humidity chamber. Slides were washed in $500 \mathrm{ml} 1 \mathrm{x}$ TBS for 10 minutes (with stirring), then incubated in secondary antibody (biotinylated for DAB staining (1:300) or Alexaflour for fluorescence (1:500; diluted in 1x TBS) for 1 hour at room temperature. For DAB staining, The Strept ABC-HRP (1:100 of each $\mathrm{A}$ and $\mathrm{B}$ in 1x DAB developing buffer) was left to conjugate for 30 mins. Slides were rinsed in $1 \mathrm{x}$ TBS and then incubated in the conjugated Strept ABC-HRP solution for 30 minutes. Slides were rinsed in $500 \mathrm{ml} 1 \mathrm{x}$ TBS for 5 minutes, with stirring, and then developed for 10 minutes in DAB solution (DAKO DAB enhancer was used for $\mathrm{pSmad1/5/9}$ at 1:300). Slides were washed under running water, counterstained with haematoxylin, and returned to the running water until nuclei turned blue. Antibodies, and the dilutions they were used at is summarised in Table 2.

For in situ hybridisation, dissected hindbrains were fixed in 4\% PFA for 1 hour (and stored up to 3 months) and stained as previously described (Myat et al., 1996) using a digoxygenin-labelled riboprobe (Roche) against Patched-1 (Ptch1). Tissue was flat mounted in 100\% glycerol and imaged from the dorsal side.

\section{Table 2: antibodies}




\begin{tabular}{llll}
\hline Target & Host species & Dilution & Source \\
\hline Phosphorylated Smad1/5/9 (pSmad) & Rabbit & $1: 100$ & CST 13820 \\
\hline Calbindin & Mouse & $1: 1000-5000$ & Swant D28K \\
\hline Phosphohistone-3 (PH3) & Rabbit & $1: 100$ & CST \\
\hline DAPI & $\mathrm{n} / \mathrm{a}$ & $\mathrm{n} / \mathrm{a}$ & Abcam \\
\hline Alexafluor-488 & Goat anti-mouse & $1: 500$ & Thermofisher \\
\hline Alexafluor-488 & Goat anti-rabbit & $1: 500$ & Thermofisher \\
\hline Alexafluor-568 & Goat anti-mouse & $1: 500$ & Thermofisher \\
\hline Alexafluor-568 & Goat anti-rabbit & $1: 500$ & Thermofisher \\
\hline
\end{tabular}

\section{Image analysis}

Sections with fluorescent labelling were imaged using a Zeiss LSM 800 confocal microscope and Z-projections compiled with ImageJ (Schneider et al., 2012). Non-fluorescent samples were imaged using a Zeiss Axioscope microscope. To represent the pial migration from the rhombic lip (Figure 4a,b) the fluorescence intensity, termed "gray value" in ImageJ, from the rhombic lip towards the midline in an area of abundant electroporation (coloured lines; Figure 4a), was plotted as a surface histogram, obtained from the plot profile plugin and a curve of best fit $\left(5^{\text {th }}\right.$ degree polynominal). ImageJ was also used to quantify the number of antigen-expressing cells per area (+ve cells $/ \mathrm{m}^{2}$ ); cells positive for $\mathrm{pSmad}$ labelling were manually counted using the cell counter plugin (Figure 1h) whereas quantification of PH3 labelling (Figure 5c,d) was done automatically by converting a compressed Z-stack to a binary image, watershed function applied and the analyse particles plugin applied to count positive cells in the sample. The area of the tissue being quantified was also measured in ImageJ and the number of + ve positive nuclei per $\mu \mathrm{m}^{2}$ was then calculated in Excel and analysed for significance in GraphPad Prism. To measure the density of DAPI + ve nuclei at the pial surface in electroporated samples (Figure 5i), individual slices from Z-stacks of each sample were processed to binary images, and a line was drawn across the pia in Image J and the fluorescent density averaged across this line using the plot profile plugin.

\section{Statistical analyses}

All data were analysed in GraphPad Prism, and non-paired parametric t-tests were carried out to identify significance.

\section{Data and Materials availability}


The human material was provided by the Joint MRC/Wellcome (MR/R006237/1) Human Developmental Biology Resource (www.hdbr.org). Human tissue used in this study was covered by a material transfer agreement between SCRI and HDBR. Samples may be requested directly from the HDBR.

\section{Acknowledgements}

We thank Andrea Munsterberg and Grant Wheeler for the Smad1EVE construct, Koichi Kawakami and Yoshiko Takahashi for the Tol2 construct, and Andrea Streit for the Smad6 construct.

\section{Competing Interests}

The authors have no competing interests.

\section{References}

Alder, J., Cho, N.K. \& Hatten, M.E. (1996) Embryonic Precursor Cells from the Rhombic Lip Are Specified to a Cerebellar Granule Neuron Identity. Neuron, 17, 389-399.

Alder, J., Lee, K.J., Jessell, T.M. \& Hatten, M.E. (1999) Generation of cerebellar granule neurons in vivo by transplantation of BMP-treated neural progenitor cells. Nat Neurosci, 2, 535-540.

Altman, J. \& Bayer, S.A. (1997) Development of the cerebellar system: In relation to its evolution, structure, and functions. CRC Press, Chapter 9 and 10.

Ayrault, O., Zhao, H., Zindy, F., Qu, C., Sherr, C.J. \& Roussel, M.F. (2010) Atoh1 inhibits neuronal differentiation and collaborates with Gli1 to generate medulloblastoma-initiating cells. Cancer Res, 70, 561827.

Azevedo, F.A., Carvalho, L.R., Grinberg, L.T., Farfel, J.M., Ferretti, R.E., Leite, R.E., Jacob Filho, W., Lent, R. \& Herculano-Houzel, S. (2009) Equal numbers of neuronal and nonneuronal cells make the human brain an isometrically scaled-up primate brain. J Comp Neurol, 513, 532-541.

Ben-Arie, N., Bellen, H.J., Armstrong, D.L., Matzuk, M.M. \& Zoghbi, H.Y. (1997) Math1 is essential for genesis of cerebellar granule neurons. Nature, 390, 169-172. 
Bier, E. \& De Robertis, E.M. (2015) BMP gradients: A paradigm for morphogen-mediated developmental patterning.Science, $\mathbf{3 4 8}$, aaa5838.

Broom, E.R., Gilthorpe, J.D., Butts, T., Campo-Paysaa, F. \& Wingate, R.J. (2012) The roof plate boundary is a bidirectional organiser of dorsal neural tube and choroid plexus development. Development, 139, 4261-4270.

Buckner, R.L. (2013) The cerebellum and cognitive function: 25 years of insight from anatomy and neuroimaging. Neuron, 80, 807-815.

Butts, T., Green, M.J. \& Wingate, R.J. (2014a) Development of the cerebellum: simple steps to make a 'little brain'. Development, 141, 4031-4041.

Butts, T., Hanzel, M. \& Wingate, R.J. (2014b) Transit amplification in the amniote cerebellum evolved via a heterochronic shift in NeuroD1 expression. Development, 141, 2791-2795.

Butts, T., Modrell, M.S., Baker, C.V. \& Wingate, R.J. (2014c) The evolution of the vertebrate cerebellum: absence of a proliferative external granule layer in a non-teleost ray-finned fish. Evol Dev, 16, 92-100.

Cajal, S.R.y. (1894) Les Nouvelles Idées sur la Structure du Système Nerveux chę l'Homme et chę les Vertébrés. C. Reinwald $\&$ Cie, Paris.

Campo-Paysaa, F., Clarke, J.D.W. \& Wingate, R.J.T. (2019) Generation of the squamous epithelial roof of the 4th ventricle. eLife, $\mathbf{8}$, e38485.

Chaplin, N., Tendeng, C. \& Wingate, R.J. (2010) Absence of an external germinal layer in zebrafish and shark reveals a distinct, anamniote ground plan of cerebellum development. J Neurosci, 30, 3048-3057.

Chizhikov, V.V., Lindgren, A.G., Currle, D.S., Rose, M.F., Monuki, E.S. \& Millen, K.J. (2006) The roof plate regulates cerebellar cell-type specification and proliferation. Development, 133, 2793-804.

Corrales, J.D., Rocco, G.L., Blaess, S., Guo, Q. \& Joyner, A.L. (2004) Spatial pattern of sonic hedgehog signaling through Gli genes during cerebellum development. Development, 131, 5581-90.

Corrales, J.D., Blaess, S., Mahoney, E.M. \& Joyner, A.L. (2006) The level of sonic hedgehog signaling regulates the complexity of cerebellar foliation. Development, 133, 1811-21.

Dahmane, N. \& Altaba, A.R. (1999) Sonic hedgehog regulates the growth and patterning of the cerebellum.

Development, 126, 3089-3100. 
Dastjerdi, F.V., Consalez, G.G. \& Hawkes, R. (2012) Pattern formation during development of the embryonic cerebellum. Front Neuroanat, 6, 10.

Di Giovannantonio, L.G., Di Salvio, M., Omodei, D., Prakash, N., Wurst, W., Pierani, A., Acampora, D. \& Simeone, A. (2014) Otx2 cell-autonomously determines dorsal mesencephalon versus cerebellum fate independently of isthmic organizing activity. Development, 141, 377-388.

Espinosa, J.S. \& Luo, L. (2008) Timing neurogenesis and differentiation: insights from quantitative clonal analyses of cerebellar granule cells. J Neurosci, 28, 2301-2312.

Famulski, J.K., Trivedi, N., Howell, D., Yang, Y., Tong, Y., Gilbertson, R. \& Solcki, D.J. (2010) Siah regulation of Pard3A controls neuronal cell adhesion during germinal zone exit. Science, 330, 1834-1838.

Fernandes, M., Antoine, M. \& Hébert, J.M. (2012) SMAD4 is essential for generating subtypes of neurons during cerebellar development. Dev Biol, 365, 82-90.

Fraser, S., Keynes, R. \& Lumsden, A. (1990) Segmentation in the chick embryo hindbrain is defined by cell lineage restrictions. Letters to Nature, 344, 431-435.

Freeman, S., Chrysostomou, E., Kawakami, K., Takahashi, Y. \& Daudet, N. (2012) Tol2-mediated gene transfer and in ovo electroporation of the otic placode: a powerful and versatile approach for investigating embryonic development and regeneration of the chicken inner ear. Methods Mol Biol, 916, 127-139.

Fuentealba, L.C., Eivers, E., Ikeda, A., Hurtado, C., Kuroda, H., Pera, E.M., De Robertis, E.M. (2007) Integrating patterning signals: Wnt/GSK3 regulates the duration of the BMP/Smad1 signal. Cell, 131, 980-93.

Gilthorpe, J.D., Papantoniou, E., Chédotal, A., Lumsden, A. \& Wingate, R.J. (2002) The migration of cerebellar rhombic lip derivatives. Development, 129, 4719-4728.

Gona, A.G. (1976) Autoradiographic studies of cerebellar histogenesis in the bullfrog tadpole during metamorphosis: the external granular layer. J Comp Neurol 165, 77-87.

Green, M.J., Myat, A.M., Emmenegger, B.A., Wechsler-Reya, R.J., Wilson, L.J. \& Wingate, R.J. (2014) Independently specified Atoh1 domains define novel developmental compartments in rhombomere 1. Development, 141, 389-398.

Haldipur, P., Aldinger, K.A., Bernardo, S., Deng, M., Timms, A.E., Overman, L.M., Winter, C., Lisgo, S.N., Razavi, F., Silvestri, E., Manganaro, L., Adle-Biassette, H., Guimiot, F., Russo, R., Kidron, D., Hof, P.R., Gerrelli, D., Lindsay, S.J., Dobyns, W.B., Glass, I.A., Alexandre, P. \& Millen, K.J. (2019) Spatiotemporal expansion of primary progenitor zones in the developing human cerebellum. Science, 366, 454-460. 
Hamburger, V. \& Hamilton, H.L. (1993) A series of normal stages in the development of the chick embryo. Developmental Dynamics, 195, 231-272.

Hansen, D.V., Lui, J.H., Parker, P.R. \& Kriegstein, A.R. (2010) Neurogenic radial glia in the outer subventricular zone of human neocortex. Nature, 464, 554-561.

Hanzel, M., Rook, V. \& Wingate, R.J.T. (2019) Mitotic granule cell precursors undergo highly dynamic morphological transitions throughout the external germinal layer of the chick cerebellum. Scientific reports, 9 , 15218.

Hatten, M.E. \& Heintz, N. (1995) Mechanisms of neural patterning and specification in the developing cerebellum. Annu. Rev. Neurosci., 18, 385-408.

Hausmann, B. \& Sievers, J. (1985) Cerebellar external granule cells are attached to the basal lamina from the onset of migration up to the end of their proliferative activity. J Comp Neurol, 241, 50-62.

Hegarty, S.V., O'Keeffe, G.W. \& Sullivan, A.M. (2013) BMP-Smad 1/5/8 signalling in the development of the nervous system. Prog Neurobiol, 109, 28-41.

Heide, M., Haffner, C., Murayama, A., Kurotaki, Y., Shinohara, H., Okano, H., Sasaki, E. \& Huttner, W.B. (2020) Human-specific $A R H G A P 11 B$ increases size and folding of primate neocortex in the fetal marmoset. Science, 369, 546-550.

Hibi, M., Matsuda, K., Takeuchi, M., Shimizu, T. \& Murakami, Y. (2017) Evolutionary mechanisms that generate morphology and neural-circuit diversity of the cerebellum. Dev Growth Differ, 59, 228-243.

Ito, M. (2000) Mechanisms of motor learning in the cerebellum. Brain Res, 886, 237-245.

Ito, M. (2006) Cerebellar circuitry as a neuronal machine. Prog Neurobiol, 78, 272-303.

Iulianella, A., Wingate, R.J., Moens, C.B. \& Capaldo, E (2019) The generation of granule cells during the development and evolution of the cerebellum. Dev Dyn, 248, 506-513.

Kaslin, J., Ganz, J., Geffarth, M., Grandel, H., Hans, S. \& Brand, M. (2009) Stem cells in the adult zebrafish cerebellum: initiation and maintenance of a novel stem cell niche. J Neurosci, 29, 6142-53.

Kiecker, C. \& Lumsden, A. (2005) Compartments and their boundaries in vertebrate brain development. Nat Rev Neurosci, 6, 553-564.

Kullman, J.A., Trivedi, N., Howell, D., Laumonnerie, C., Nguyen, V., Banerjee, S.S., Stabley, D.R., Shirinifard, A., Rowitch, D.H. \& Solecki, D.J. (2020) Oxygen tension and the WHL-Hif1 $\alpha$ pathway determine onset of neuronal polarisation and cerebellar germinal zone exit. Neuron, 106, 607-623. 
Legué, E., Gottshall, J.L., Jaumouillé, E., Roselló-Díez, A., Shi, W., Barraza, L.H., Washington, S., Grant, R.L. \& Joyner, A.L. (2016) Differential timing of granule cell production during cerebellum development underlies generation of the foliation pattern. Neural Dev, $\mathbf{1 1}, 17$.

Legué, E., Riedel, E. \& Joyner, A.L. (2015) Clonal analysis reveals granule cell behaviors and compartmentalization that determine the folded morphology of the cerebellum. Development, 142, 1661-71.

Lewis, P.M., Gritli-Linde, A., Smeyne, R., Kottmann, A. \& McMahon, A.P. (2004) Sonic hedgehog signaling is required for expansion of granule neuron precursors and patterning of the mouse cerebellum. Dev Biol, 270, 393-410.

Ma, T.C., Vong, K.I. \& Kwan, K.M. (2020) Spatiotemporal Decline of BMP Signaling Activity in Neural Progenitors Mediates Fate Transition and Safeguards Neurogenesis. Cell Rep, 30, 3616-3624.e4.

Machold, R. \& Fishell, G. (2005) Math1 is expressed in temporally discrete pools of cerebellar rhombic-lip neural progenitors. Neuron, $48,17-24$.

Machold, R., Klein, C. \& Fishell, G. (2011) Genes expressed in Atoh1 neuronal lineages arising from the r1/isthmus rhombic lip. Gene Expr Patterns, 11, 349-359.

Machold, R.P., Kittell, D.J. \& Fishell, G.J. (2007) Antagonism between Notch and bone morphogenetic protein receptor signaling regulates neurogenesis in the cerebellar rhombic lip. Neural Dev, 2, 5.

Martinez, S., Andreu, A., Mecklenburg, N. \& Echevarria, D. (2013) Cellular and molecular basis of cerebellar development. Front Neuroanat, 7, 18.

Martinez, S., Crossley, P.H., I., C., Rubenstein, J.L.R. \& Martin, G.R. (1999) FGF8 induces formation of an ectopic isthmic organizer and isthmocerebellar development via a repressive effect on Otx2 expression. Development, 126, 1189-1200.

Millard, N.E. \& De Braganca, K.C. (2016) Medulloblastoma. J Child Neurol, 31, 1341-1353.

Miyata, T., Maeda, T. \& Lee, J.E. (1999) NeuroD is required for differentiation of the granule cells in the cerebellum and hippocampus. Genes \& Development, 13, 1647-1652.

Myat, A., Henrique, D., Ish-Horowicz, D. \& Lewis, J. (1996) A Chick Homologue of Serrate and Its Relationship with Notch and Delta Homologues during Central Neurogenesis. Dev Biol, 174, 223-247.

Nakashima, K., Umeshima, H. \& Kengaku, M. (2015) Cerebellar granule cells are predominantly generated by terminal symmetric divisions of granule cell precursors. Dev Dyn, 244, 748-58. 
Noctor, S.C., Martínez-Cerdeño, V., Ivic, L. \& Kriegstein, A.R. (2004) Cortical neurons arise in symmetric and asymmetric division zones and migrate through specific phases. Nat Neurosci, 7,136-44.

Owa, T., Taya, S., Miyashita, S., Yamashita, M., Adachi, T., Yamada, K., Yokoyama, M., Aida, S., Nishioka, T., Inoue, Y.U., Goitsuka, R., Nakamura, T., Inoue, T., Kaibuchi, K. \& Hoshino, M. (2018) Meis1 Coordinates Cerebellar Granule Cell Development by Regulating Pax6 Transcription, BMP Signaling and Atoh1 Degradation. J Neurosci, 38, 1277-1294.

Paulin, M.G. (1993) The role of the cerebellum in motor control and perception. Brain Behav Evol, 4, 39-50.

Pietsch, T., Waha, A., Koch, A., Kraus, J., Albrecht, S., Tonn, J., Sörensen, N., Berthold, F., Henk, B., Schmandt, N., Wolf, H.K., von Deimling, A., Wainwright, B., Chenevix-Trench, G., Wiestler, O.D. \& Wicking, C. (1997) Medulloblastomas of the desmoplastic variant carry mutations of the human homologue of Drosophila patched. Cancer Res, 57, 2085-8.

Qin, L., Wine-Lee, L., Ahn, K.J. \& Crenshaw, E.B. 3rd. (2006) Genetic analyses demonstrate that bone morphogenetic protein signaling is required for embryonic cerebellar development. J Neurosci 26, 1896-905.

Raffel, C., Jenkins, R.B., Frederick, L., Hebrink, D., Alderete, B., Fults, D.W. \& James, C.D. (1997) Sporadic medulloblastomas contain PTCH mutations. Cancer Res 57, 842-5.

Rios, I., Alvarez-Rodriguez, R., Marti, E. \& Pons, S. (2004) Bmp2 antagonizes sonic hedgehog-mediated proliferation of cerebellar granule neurones through Smad5 signalling. Development, 131, 3159-3168.

Sato, Y., Kasai, T., Nakagawa, S., Tanabe, K., Watanabe, T., Kawakami, K. \& Takahashi, Y. (2007) Stable integration and conditional expression of electroporated transgenes in chicken embryos. Dev Biol, 305, 616624.

Saxena, M., Agnihotri, N. \& Sen, J. (2018) Perturbation of canonical and non-canonical BMP signaling affects migration, polarity and dendritogenesis of mouse cortical neurons. Development, 145, dev147157.

Schneider, C.A., Rasband, W.S., \& Eliceiri, K.W. (2012) NIH Image to ImageJ: 25 years of image analysis. Nat Methods, 9, 671-5.

Shaw, J.C., Berry, M.J., Dyson, R.M., Crombie, G.K., Hirst, J.J. \& Palliser, H.K. (2019) Reduced Neurosteroid Exposure Following Preterm Birth and Its' Contribution to Neurological Impairment: A Novel Avenue for Preventative Therapies. Front Physiol, 10, 599.

Singh, S. \& Solecki, D.J. (2015) Polarity transitions during neurogenesis and germinal zone exit in the developing central nervous system. Front Cell Neurosci, 9, 62. 
Singh, S., Howell, D., Trivedi, N., Kessler, K., Ong, T., Rosamaninho, P., Raposo, A.A., Robinson, G., Roussel, M.F., Castro, D.S. \& Solecki, D.J. (2016) Zeb1 controls neuron differentiation and germinal zone exit by a mesenchymal-epithelial-like transition. Elife, 5, e12717.

Song, J., McColl, J., Camp, E., Kennerley, N., Mok, G.F., McCormick, D., Grocott, T., Wheeler, G.N. \& Münsterberg, A.E. (2014) Smad1 transcription factor integrates BMP2 and Wnt3a signals in migrating cardiac progenitor cells. Proc Natl Acad Sci U S A, 111, 7337-42.

Sudarov, A. \& Joyner, A.L. (2007) Cerebellum morphogenesis: the foliation pattern is orchestrated by multicellular anchoring centers. Neural Dev, 2, 26.

Tong, K.K. \& Kwan, K.M. (2013) Common partner Smad-independent canonical bone morphogenetic protein signaling in the specification process of the anterior rhombic lip during cerebellum development. Mol Cell Biol, 33, 1925-37.

Tong, K.K., Ma, T.C. \& Kwan, K.M. (2015) BMP/Smad signaling and embryonic cerebellum development: stem cell specification and heterogeneity of anterior rhombic lip. Dev Growth Differ, 57, 121-134.

Trivedi, N., Stabley, D.R., Cain, B., Howell, D., Laumonnerie, C., Ramahi, J.S., Temirov, J., Kerekes, R.A., Gordon-Weeks, P.R. \& Solecki, D.J. (2017) Drebrin-mediated microtubule-actomyosin coupling steers cerebellar granule neuron nucleokinesis and migration pathway selection. Nat Commun, 8, 14484.

Vorechovský, I., Tingby, O., Hartman, M., Strömberg, B., Nister, M., Collins, V.P. \& Toftgård, R. (1997) Somatic mutations in the human homologue of Drosophila patched in primitive neuroectodermal tumours.

Oncogene, 15, 361-6.

Wagner, M.J., Kim, T.H., Savall, J., Schnitzer, M.J. \& Luo, L. (2017) Cerebellar granule cells encode the expectation of reward. Nature, 544, 96-100.

Wallace, V.A. (1999) Purkinje-cell-derived Sonic hedgehog regulates granule neuron precursor cell proliferation in the developing mouse cerebellum. Curr Biol 9, 445-8.

Wang, L., Hou, S. \& Han, Y.G. (2016) Hedgehog signaling promotes basal progenitor expansion and the growth and folding of the neocortex. Nat Neurosci, 19, 888-96.

Wang, S.S., Kloth, A.D. \& Badura, A. (2014) The cerebellum, sensitive periods, and autism. Neuron, 83, 518-532.

Wang, V.Y., Rose, M.F. \& Zoghbi, H.Y. (2005) Math1 expression redefines the rhombic lip derivatives and reveals novel lineages within the brainstem and cerebellum. Neuron, 48, 31-43.

Wechsler-Reya, R.J. \& Scott, M.P. (1999) Control of Neuronal Precursor Proliferation in the Cerebellum by Sonic Hedgehog. Neuron, 22, 103-114. 
Wilson, L.J. \& Wingate, R.J. (2006) Temporal identity transition in the avian cerebellar rhombic lip. Dev Biol, 297, 508-521.

Wingate, R.J. (2001) The rhombic lip and early cerebellar development. Current Opinion in Neurobiology, 11, 82-88.

Wingate, R.J. \& Hatten, M.E. (1999) The role of the rhombic lip in avian cerebellum development. Development, 126, 4395-4404.

Xie, Z., Chen, Y., Li, Z., Bai, G., Zhu, Y., Yan, R., Tan, F., Chen, Y.G., Guillemot, F., Li, L. \& Jing, N. (2011) Smad6 promotes neuronal differentiation in the intermediate zone of the dorsal neural tube by inhibition of the Wnt/beta-catenin pathway. Proc Natl Acad Sci U S A, 108, 12119-24.

Yamada, M., Seto, Y., Taya, S., Owa, T., Inoue, Y.U., Inoue, T., Kawaguchi, Y., Nabeshima, Y. \& Hoshino, M. (2014) Specification of spatial identities of cerebellar neuron progenitors by ptf1a and atoh1 for proper production of GABAergic and glutamatergic neurons. J Neurosci, 34, 4786-4800.

Yang, R., Wang, M., Wang, J., Huang, X., Yang, R. \& Gao, W.Q. (2015) Cell Division Mode Change Mediates the Regulation of Cerebellar GranuleNeurogenesis Controlled by the Sonic Hedgehog Signaling. Stem Cell Reports, 5, 816-828.

Zanin, J.P., Abercrombie, E. \& Friedman, W.J. (2016) Proneurotrophin-3 promotes cell cycle withdrawal of developing cerebellar granule cell progenitors via the p 75 neurotrophin receptor. Elife, 5, e16654.

Zanin, J.P., Verpeut, J.L., Li, Y., Shiflett, M.W., Wang, S.S., Santhakumar, V. \& Friedman, W.J. (2019) The p75NTR Influences Cerebellar Circuit Development and Adult Behavior via Regulation of Cell Cycle Duration of Granule Cell Progenitors. J Neurosii, 39, 9119-9129.

Zhao, H., Ayrault, O., Zindy, F., Kim, J.H. \& Roussel, M.F. (2008) Post-transcriptional down-regulation of Atoh1/Math1 by bone morphogenic proteins suppresses medulloblastoma development. Genes Dev, 22, $722-7$.

Zhu, G., Mehler, M.F., Zhao, J., Yung, S.Y. \& Kessler, J.A. (1999) Sonic Hedgehog and BMP2 Exert Opposing Actions on Proliferation and Differentiation of Embryonic Neural Progenitor Cells. Developmental Biology, 215, 118-219. 